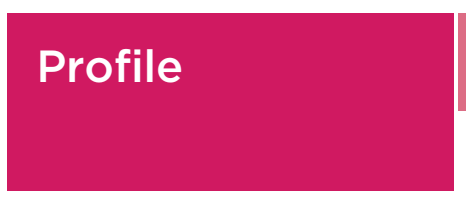

\title{
Rapidly changing endocrine oncology research: personal reflection of the past, present and future times
}

\section{Zoran Culig}

Experimental Urology, Department of Urology, Innsbruck Medical University, Anichstrasse 35, A-6020 Innsbruck, Austria

Correspondence

should be addressed

to Z Culig

Email

zoran.culig@i-med.ac.at

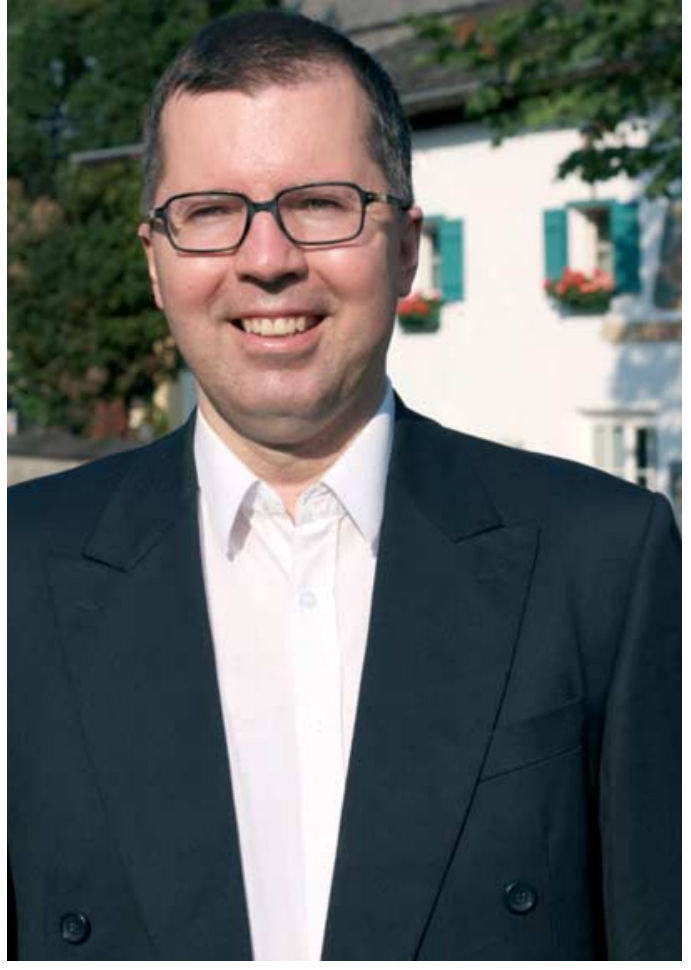

After 20 years in prostate cancer research, this may be a good opportunity to critically re-analyse past and present times, and to understand that many personal interactions occur as a consequence of events that are non-sciencerelated. For a young researcher who originates from a family with no medical background, such as mine, it has been perhaps easier to develop novel concepts in a research field, which I selected during medical studies on the basis of an interest in hormone action.
My research philosophy in the 90s was, perhaps typically for a European, strongly influenced by initial contacts in the US scientific conferences in North America, which also attracted many people from the world of business and politics. In fact, one of the events that opened new perspectives in research to me was a conference organized by the National Institutes of Health in Washington DC in a US national historical landmark, the hotel Mayflower. There was not only science but also a special atmosphere reminiscent of the old world of the 19th century, which made this conference so memorable. As a speaker, I had the opportunity to interact with many leaders in the field, such as Donald Tindall and Leland Chung, during my earlier research activities. Meetings of CaP CURE (now the Prostate Cancer Foundation) in the unique atmosphere of Lake Tahoe followed. It was very unusual to see that political and government organizations, which in the 'Old Continent' would not normally be involved in research, became partners in a selection of scientific projects, thus providing active support. From today's perspective, this period could be seen as a time of great enthusiasm. America wanted to learn more about devastating diseases and had a natural optimism that a cure was possible. Although it may be difficult to see a clear connection, I also believe that the recent period of high investment in oncological science, including prostate cancer, was a consequence of a relaxed global economical and political situation. There was no sign of any kind of 'crisis' and the opportunities for new markets became greater. Economic growth could be compared with the larger research groups in the United States, which impressed me a lot during earlier stages of my career.

Published by Bioscientifica Ltd 
Now, I am becoming more conservative in my judgement of what is called 'optimal laboratory size'. That positive international environment was reflected at the Department of Urology of Innsbruck University in which close connections between the experimental and clinical scientists have been established. The Department enjoyed world-class visitors such as Donald Coffey whose words of wisdom were always appreciated. In comparison to the present situation, the transfer of scientists from Europe to the US was more frequent; people decided to move because of a relatively simple academic structure in the US and earlier recognition of new research achievements, which always impressed younger research faculty members. Thus, that first phase of my research was always like a search for new concepts. Because of frequent contacts with clinical urologists, I have been confronted many times with the question 'what is the clinical consequence of your research?'. The answer to this question is at least in part a positive one: without androgen receptor research, and after decades of the use of inappropriate models, the scientific community would not have been so focused on the development of abiraterone acetate or enzalutamide. Thus, there has obviously been a long period of time between the elucidation of androgen receptor function in therapyresistant disease and the development of novel therapies. We can show patients that the investment in research in the past is visible now. The communication between researchers and patients is not sufficiently developed in Europe. However, we hope that novel training possibilities for young researchers, as promoted by the European Union, will improve the situation in scientific communication.

My academic achievements were recognized by the University and I was promoted to the level of Associate Professor in 1999. From that time, a new period of my research has started, a period in which I have become much more involved in fund-raising activities and recruiting fellow researchers. I have also broadened my research spectrum and, in addition to the androgensignalling pathway, included cytokine biology in several projects, some of which are ongoing. From these studies, I learned that the answer to clinical problems is not black and white. There are many lessons from preclinical research for the proper design of clinical trials. It seems that some important preclinical recognitions are lost. The interactions between interleukin- 6 and the androgen signalling pathway are still not clear enough and it is particularly difficult to interpret the implications in early prostate carcinogenesis.
In this period, however, I learned that a peak in the society and public support for prostate cancer researchers had been achieved. Both Europe and the US have been affected and there is not a light at the end of the tunnel. Public organizations and agencies are faced with the problem of how to distribute a reduced amount of money to a growing number of competent researchers. Several negative consequences of bad economic developments are obvious in laboratory research. It is important to have a strategy, which considers several sources of funding with exit variants. The system of grant distribution has reached a stage of many limitations and we all see that our time is more and more unreasonably spent. This problem affects not only principal investigators but also grant reviewers and support staff. The question of whether lengthy meetings and extensive travel for peer reviewers is still justified to select a very small number of projects (frequently below 10\%) is a legitimate one. Our employers, Universities, will inevitably be confronted with the question of what they get as a result of the investment in human resources. I doubt that a large number of proposals that are not approved by external bodies may be a satisfactory answer. A more sustained funding of successful researchers does not appear to be established in academia. At the end, there is a reduced enthusiasm for scientific research and exchange of information. A typical symptom of increasing crisis in scientific management could be seen from my perspective as a Scientific Editor. Although the Internet helped us with efficient submission and evaluation systems, I know a number of colleagues who are overcommitted and unable to read manuscripts as reviewers and provide critical assessment. Another problem that is increasingly recognized is an attempt to commercialize basic research. American Universities are perhaps more experienced in protecting their interests compared with their European counterparts. The different interests between the academic and pharmaceutical sector are obvious and there is a discrepancy between the declared policies of grant agencies and real development. In particular, transnational projects frequently call for an active participation of a commercial entity. Many difficulties in such partnerships cannot be neglected. I remember a potentially interesting workshop about the partnership; however, it is interesting to note that in Europe, big grant calls are dependent on active industrial participation, which raises questions about publication policy and intellectual property rights. From the practical point of view, such partnership expectations appear to be a little bit naive.

Published by Bioscientifica Ltd. 
I have had the opportunity to interact with several postdocs and PhD students. Young people are of course different personalities and bring personal views and ideas to the research laboratory. Now it is a great pleasure to learn that some of them show a clear determination in research and social life. It is always a challenge to identify the right person after the interview. It is usually good to exchange opinions with junior laboratory members who will work with a new colleague. Social interactions are very important for the general success of the laboratory and I learned that a proactive policy is appreciated. It is a pleasure to see how young members of the group are recognized with international awards, some of them after a relatively short period of research experience. It was always important for me to see science as a collective endeavour.

Let me mention two researchers from my laboratory. A considerable amount of $\mathrm{PhD}$ student supervision in my laboratory has been done by postdocs Frédéric Santer and Martin Puhr, whose own contributions are recognized in the urology research community. It became a difficult issue for me to provide good advice to a postdoc. For a new $\mathrm{PhD}$, there may be more opportunities because mobility grants are still available. It is important to have a good overview of what is going on. However, one should recognize that in the rapidly changing prostate cancer research field, there are some 'trends' that may be simply a result of dominating technologies and advancements, which have little in common with the focus of investigation. It is also understandable that many postdocs need more stability and that their knowledge is generated over many years of hard laboratory work.

A researcher should, if possible, consider performing services for the scientific community and this is what I have learned with the European Section for Urological Research (ESUR). First, my intention when I became a
Board Member in 2004 and now as a Chair was to attract the best brains in the urological community in Europe. These gatherings also have a special character and have marked our progression from ESUR to successful European consortia such as PRIMA, CANCURE and PRO-NEST. Some of these projects were initially discussed in hotel restaurants and other places where social meetings were organized. I hope that my colleagues on the Board and I have created an environment to our meetings that is inviting and that increases the reputation of Europe in basic and translational urological research. I am also proud of establishing the Dominique Chopin Award during my term on the Board. With this award, we honour true leaders in European urology research who had the vision of how to discuss topics relevant to both basic scientists and to clinicians. So far, we have selected Jan Trapman, Norman Maitland, Natasha Kyprianou, Tapio Visakorpi and Craig Robson as Chopin awardees. It is a great pleasure to see that the European Association of Urology is developing well. I still remember the days when I started to review for their journal European Urology, which was not known to the leaders in the experimental field. Nowadays, the publication of a scientific article in the journal is considered a great honour.

Although a lot of work has been done, I see at present my obligations are the promotion of the most talented people in my laboratory and securing their professional stability and career. Success may be a long way in the future.

Declaration of interest

The author declares that there is no conflict of interest that could be perceived as prejudicing the impartiality of this work.

\section{Funding}

This work did not receive any specific grant from any funding agency in the public, commercial or not-for-profit sector. (c) 2013 Society for Endocrinology Printed in Great Britain
Published by Bioscientifica Ltd. 